\title{
PENINGKATAN KEMANDIRIAN BELAJAR MATEMATIKA MELALUI PENERAPAN PENDEKATAN SCAFFOLDING
}

\section{IMPROVING MATHEMATICS SELF REGULATED LEARNING THROUGH THE APPLICATION OF A SCAFFOLDING APPROACH}

\author{
SETIARSIH
}

SMAN 14 Jakarta

\begin{abstract}
Received: March 09, 2021

Self Regulated learning during the covid-19 pandemic is required, therefore is necessary to use Revised: September 30, 2021 the right learning model. The scaffolding learning method can provide students to be active in Accepted: November 26, 2021 distance learning. The purpose of this study was to see the improvement of students' SRL through the scaffolding method. It used a quasi-experimental technique with random sampling. The study was conducted class $X$ at a Public High School in East Jakarta. The samples consisted 1 experimental and 1 control group. SRL data was obtained SRL instruments. Instrument has 4 dimensions wich has a Cronbach alpha value ranging from 0.711 to 0.887 . Hypothesis testing using the SPSS 21 t-test obtained data that thitung=2.152, and $p$-value $0.036 / 2<0.05$ then $\mathrm{Ho}$ was rejected. The conclusion of this study is that students SRL through the scaffolding approach is higher than the conventional method
\end{abstract}

\begin{abstract}
Abstrak.
Kemandirian belajar (SRL) pada masa pandemi covid-19 sangat diperlukan, karena itu perlu memperhatikan model pembelajaran yang tepat. Metode pembelajaran scaffolding dapat memberikan solusi agar siswa aktif dalam pembelajaran jarak jauh. Tujuan penelitian ini untuk melihat peningkatan SRL siswa melalui penerapan metode scaffolding. Metode penelitan menggunakan quasi eksperimen dengan teknik pengambilan sampel random sampling. Penelitian dilakukan di kelas X SMAN di bilangan Jakarta Timur. Jumlah sampel yang digunakan terdiri dari 1 kelompok eksperimen dan 1 kelompok kontrol. Data kemandirian belajar diperoleh melalui instrumen kemandirian belajar. Instrumen SRL memiliki 4 dimensi yang mana tiap dimensi memiliki nilai Alpha Cronbach berkisar dari 0,711 sampai 0,887. Pengujian hipotesis dengan menggunakan program SPSS 21 uji-t mendapatkan data bahwa thitung=2,152, dan $p$-value $=0,036 / 2<0.05$ maka Ho ditolak. Kesimpulan penelitian ini adalah kemandirian belajar siswa yang diberikan pendekatan scaffolding lebih tinggi dibandingkan dengan metode konvensional
\end{abstract}

Keywords: $\quad$ self regulated learning, scaffolding, learning outcomes

Kata kunci: Kemandirian Belajar, Scaffolding, Hasil belajar

$\left(^{\star}\right)$ Corresponding Author: $\quad$ tiarsma14@gmail.com

How to Cite: Setiarsih, (2021). Peningkatan Kemandirian Belajar Matematika Melalui Penerapan Pendekatan Scaffolding. Jurnal Lingkar Mutu Pendidikan, 18 (2), 192-199. https://doi.org/10.54124/ilmp.v18i1.12

\section{PENDAHULUAN}

Saat ini dunia sedang dilanda pandemik covid-19 yang menyebabkan layanan pendidikan harus berubah dan tentunya aspek- aspek yang terkait dengan pembelajaran di kelas juga harus mengikuti. Pendidikan menjadi salah satu yang tidak boleh berhenti pelaksanaannya selama masa pandemi covid ini. Sekolah bisa ditutup kegiatannya namun pembelajaran tetap harus dilaksanakan secara daring. Pembelajaran yang biasanya dilakukan dengan proses tatap muka langsung beralih ke pembelajaran daring tanpa proses bertahap. Pembelajaran jarak jauh yang dilakukan menggunakan berbagai macam moda daring diantaranya Google Classroom, Google Meet, Zoom, Quizizz dan Learning Management System (LMS) lainnya. Pada awal pandemi, pembelajaran dilakukan dengan kemampuan guru apa adanya karena tanpa proses persiapan. Namun kemudian di awal tahun ajaran baru, guru gencar diberikan pelatihan LMS guna menunjang pelaksanaan jarak jauh ini. Pemerintah pun memberikan 
rambu-rambu pelaksanaan pembelajaran jarak jauh ini, yang mana ketercapaian kurikulum tidak harus dicapai selama pembelajaran daring ini.

Tahap awal pembelajaran jarak jauh yang tanpa persiapan sudah terlewati, namun masih didapati bahwa siswa mengalami hambatan dalam proses pembelajaran daring ini. Hambatan belajar bukan hanya dari segi perangkat belajar yang kurang memadai, namun dari kemandirian belajar siswa sendiri. Dari survey yang dilakukan guru bimbingan konseling sekolah ditemukan siswa yang mengalami kegagalan dalam pemahaman konsep materi yang diberikan guru dalam pembelajaran daring melalui berbagai macam moda pembelajaran jarak jauh. Siswa masih belum bisa lepas dari kebiasaan lama sebelum pandemi, yang mana siswa bisa mendapat bantuan atau bimbingan oleh guru di kelas ketika memahami suatu konsep. Pandemi ini memaksa siswa harus belajar lebih banyak mandiri. Menyadari pentingnya kemandirian belajar yang dilakukan oleh siswa siswa, maka guru harus mengupayakan penerapan pembelajaran yang bisa mendorong siswa untuk mandiri dalam belajarnya. Penerapan pembelajaran yang memungkinkan dapat memberikan kondisi belajar siswa aktif adalah dengan pembelajaran melalui penerapan scaffolding. Pembelajaran Scaffolding diartikan sebagai suatu teknik pemberian dukungan belajar, yang dilakukan pada tahap awal untuk mendorong siswa agar dapat belajar secara mandiri.

Kemandirian belajar (self regulated learning) yang menjadi salah satu faktor internal yang mempengaruhi hasil belajar matematika. Menurut Hargis (dalam Sumarni \& Sumarmo, 2016). Siswa yang memiliki kemandirian belajar yang tinggi cenderung belajar lebih baik dalam pengawasannya sendiri dari pada dalam pengawasan program, serta mampu memantau, mengevaluasi, dan mengatur tugas dan waktu belajar belajarnya secara efisien. Menurut (Cleary and Zimmerman 2004) kemandirian belajar didefinisikan sebagai pikiran, perasaan, dan perilaku yang dihasilkan sendiri yang direncanakan dan secara siklus diadaptasi berdasarkan umpan balik kinerja untuk mencapai tujuan yang ditetapkan sendiri. Menurut (Meyer 2010) menyatakan keuntungan yang dapat dicapai siswa atau manfaat dari belajar mandiri: (1) meningkatkan motivasi siswa dan kepercayaan diri dalam pembelajaran pribadi mereka serta kesadaran siswa akan keterbatasan dan kemampuan mereka untuk mengelola pembelajaran mereka, dan (2) memungkinkan mereka untuk merencanakan dan mengatur tujuan untuk pembelajaran mereka.

Beberapa penelitian tentang pembelajaran yang menggunakan teknik scaffolding sudah dilakukan. Hasil penelitian (Pramudyo Kusworo 2009) mengemukakan bahwa penerapan scaffolding akan mendorong siswa untuk mengasah pemikirannya secara mandiri yang pada akhirnya akan dapat meningkatkan kemampuan berpikir siswa, melatih siswa untuk bekerjasama bertukar pikiran dan berbagi ide sehingga akan diperoleh pengetahuan yang lebih dibandingkan jika belajar sendiri. Penelitian yang dilakukan (Nurhayati 2017), menyatakan bahwa Kemandirian belajar siswa untuk pembelajaran yang menerapkan scaffolding termasuk kategori tinggi.

Berdasarkan beberapa permasalahan di atas dan fokus penelitian ini, maka tujuan penelitian ini adalah untuk mengetahui peningkatan kemandirian belajar matematika siswa yang diberikan penerapan pembelajaran scaffolding dengan yang konvensional.

\section{METODE PENELITIAN}

Penelitian ini dilakukan pada tahun pelajaran 2020/2021 di semester genap di sebuah SMA Negeri di Jakarta. Populasi penelitian ini adalah siswa kelas $X$ yang melibatkan 5 (lima) kelas sebagai sampel. Kelas X MIPA 1 dan 3 sebagai kelas eksperimen dan kelas X MIPA 2, 4, dan 5 sebagai kelas kontrol. Namun penelitian ini hanya melakukan pengolahan data pada 1(satu) kelas eksperimen dan 1(satu) kelas kontrol.

Jenis penelitian kuantitatif menggunakan metode quasi eksperimen dengan melibatkan dua kelas secara random sampling yang bertujuan agar data yang diperoleh lebih representatif. Teknik pengumpulan data menggunakan model dokumentasi, angket dan model tes. Tes digunakan untuk memperoleh data mengenai hasil belajar siswa setelah diberikan penerapan pendekatan scaffholding.

Data SRL diperoleh dari hasil instrument Self Regulated Learning. Siswa mendapatkan tes SRL menggunakan instrumen yang diadaptasi dari peneliti sebelumnya (Zhao and Panda 2018). Instrumen ini terdiri dari 4 dimensi, masing-masing dimensi memiliki derajat reliabilitasnya. Penelitian ini memiliki 
variabel terikatnya adalah kemandirian belajar (Self Regulated Learning) dan variabel bebasnya adalah penerapan pendekatan belajar scaffholding.

Penelitian ini terdiri dari dua bagian. Bagian pertama adalah presentasi pengenalan pendekatan scaffholding dalam matematika. Bagian kedua dengan menerapkan intervensi kelas. Para siswa juga di minta untuk menulis tentang perasaan mereka, pemahaman dan harapan mereka tentang situasi sebelum mereka memulai siklus tes. Setelah mengalami siklus tes siswa juga kembali diminta untuk menuliskan kembali tentang perasaan mereka, pemahaman dan harapan mereka setelah mengikuti siklus tersebut serta pro dan kontranya. Catatan lapangan tentang percakapan informal dibuat untuk meningkatkan akurasi proses analisis.

Tabel 1. Fase Penerapan Pendekatan Scaffholding

\begin{tabular}{|c|c|}
\hline Fase & Langkah pembelajaran \\
\hline \multirow[t]{2}{*}{ Fase persiapan } & $\begin{array}{l}\text { 1. Guru memunculkan suatu permasalahan. Guru memberikan sejumlah soal yang memiliki tingkat } \\
\text { kesulitan berbeda. }\end{array}$ \\
\hline & $\begin{array}{l}\text { 2. Tugaskan siswa mencari penyelesaian (belajar individu), biarkan siswa dalam kesulitan karena akan } \\
\text { membantu akan membantu siswa berpikir lebih dalam }\end{array}$ \\
\hline \multirow[t]{4}{*}{ Fase presentasi } & 1. Siswa mendesain langkah- langkah penyelesaian \\
\hline & $\begin{array}{l}\text { 1. Saat siswa memberikan kode sudah sangat kesulitan dan tidak sanggup menyelesaikannya kemudian } \\
\text { guru menggunakan pendekatan scaffholding dengan memancing pemikiran siswa berpikir lebih } \\
\text { aktif melalui pertanyaan dan menuntunnya tahap demi tahap untuk menyelesaikannya. Generalisasi } \\
\text { konsep haruslah dari pemikiran siswa. }\end{array}$ \\
\hline & $\begin{array}{l}\text { 2. Tugaskan siswa untuk saling tukar pendapat dengan rekan- rekannya dan saling membandingkan } \\
\text { pendapat mereka. }\end{array}$ \\
\hline & $\begin{array}{l}\text { 3. Cari pendapat siswa yang mendekati dan lakukan negosiasi dengan semua siswa agar semua memiliki } \\
\text { pandangan yang sama. }\end{array}$ \\
\hline \multirow{2}{*}{ Fase Refleksi } & $\begin{array}{l}\text { 4. Biarkan siswa membuat kesimpulan sendiri berdasarkan hasil penjelasan antara siswa dengan siswa } \\
\text { dan antara siswa dengan guru }\end{array}$ \\
\hline & 5. Melakukan pembuktian terhadap materi yang sedang di hadapi berdasarkah kesimpulan yang dibuat \\
\hline
\end{tabular}

Periode pengajaran dikelas eksperimen dengan penerapan pendekatan scaffholding dilakukan selama 4 minggu. Pada minggu pertama sebelum dilakukan penerapan pendekatan scaffholding, guru menjelaskan teknik pendekatan scaffholding kepada siswa dan pada minggu yang sama juga dilakukan pretest angket self regulated learning dan tes matematika yang sudah ada.

Pertemuan pertama dilakukan pada minggu ke-2 bulan Oktober dengan memberikan pretest materi persamaan logaritma dan pertidaksamaan logaritma dan pretest kemandirian belajar kepada kelas eksperimen.

Pada pertemuan kedua guru memberikan permasalahan persamaan logaritma dengan perlakuan scaffholding kepada kelas eksperimen. Setiap minggu guru melakukan evaluasi dengan meminta siswa menulis tentang perasaan mereka, pemahaman dan harapan mereka setelah mengikuti siklus tersebut serta pro dan kontranya dalam jurnal di Google Forms.

Pada pertemuan ke-3 guru kembali melakukan penerapan scaffholding dengan menggunakan permasalahan persamaan logaritma yang berbeda kepada kelas eksperimen. Guru meminta siswa melakukan pengisian jurnal kegiatan belajar di Google Forms.

Pada pertemuan ke-4 guru memberikan permasalahan kembali mengenai materi pertidaksamaan logaritma dengan memberikan penerapan scaffholding kembali kepada siswa. Siswa kemudian juga diminta mengisi siswa mengisi jurnal Google Forms mengenai evaluasi pembelajaran hari tersebut.

Pada pertemuan ke- 5 guru memberikan permasalahan kembali mengenai materi pertidaksamaan logaritma dengan memberikan penerapan scaffholding kembali kepada siswa. Siswa kemudian juga diminta mengisi siswa mengisi jurnal Google Forms. mengenai evaluasi pembelajaran hari tersebut.

Pertemuan ke-6 Guru melakukan post test materi persamaan dan pertidaksamaan logaritma dan post-test angket kemandirian belajar kepada siswa pada kelas eksperimen. 


\section{HASIL DAN PEMBAHASAN}

Dalam penelitian ini, peneliti menggunakan instrumen yang dikembangkan oleh Zhao Chen Panda dengan skala likert, skala SRL yang terdiri dari empat dimensi tingkat pertama: (1) Plan; (2) Control; (3) Regulation; dan (4) Evaluation. Setiap dimensi tingkat pertama berisi lima dimensi tingkat kedua. Dimensi tingkat kedua mengacu pada proses pembelajaran mandiri. Setelah dianalisis akhir, skala terakhir berisi 54 item yang mencakup empat tingkat pertama dimensi (1) Plan; (2) Control; (3) Regulation; dan (4) Evaluation. dan masing-masing terdiri dari tiga dimensi level (konten pembelajaran, sumber belajar dan hasil belajar). Skala terakhir termasuk 11 item untuk Plan, 13 item untuk Control, 14 item untuk Regulation dan 16 item untuk Evaluation. Skala SRL tsb kemudian diuji validitas isi dan konstruk oleh dosen dan mahasiswa sebelum disebarkan ke sampel penelitian. Peneliti melakukan tes ulang untuk melihat reliabilitas tiap faktor skala SRL tersebut dan menentukan statistik deskriptifnya seperti tabel berikut:

Tabel 2. Reliabilitas Tiap Faktor Skala SRL

\begin{tabular}{lrrr}
\hline Dimensi SRL & Cronbach's Alpha & Means & SD \\
\hline Plan & 0,784 & 42,0263 & 4,38835 \\
Control & 0,711 & 49,3224 & 4,72783 \\
Regulation & 0,797 & 51,4641 & 5,46884 \\
Evaluation & 0,887 & 60,1053 & 7,12626 \\
\hline
\end{tabular}

Berdasarkan tabel 2 diatas menunjukan nilai Cronbach's Alpha tiap faktor Skala SRL berada pada interval 0,711 sampai dengan 0,887.

Tabel 3. Validitas Instrumen SRL dengan Pearson

\begin{tabular}{|c|c|c|c|}
\hline Dimensi SRL & $\begin{array}{c}\text { No } \\
\text { angket }\end{array}$ & Uraian & $\begin{array}{c}\text { Nilai } \\
\text { Korelasi } \\
\text { Pearson }\end{array}$ \\
\hline Kemampuan & & Sumber Belajar & \\
\hline \multirow[t]{13}{*}{ perencanaan } & 1 & $\begin{array}{l}\text { Saya mencoba untuk mencari sendiri dan mempelajari materi pelajaran sebelum kegiatan } \\
\text { belajar mengajar berlangsung }\end{array}$ & $.604^{* *}$ \\
\hline & 2 & $\begin{array}{l}\text { Sebelum pembelajaran jarak jauh dilaksanakan, saya login ke platform pembelajaran atau } \\
\text { situs web program untuk mempelajari berbagai fungsi yang ada dalam platform tersebut }\end{array}$ & $.447^{* *}$ \\
\hline & 3 & Saya memilih metode belajar yang sesuai dengan gaya belajar saya & $.421^{* *}$ \\
\hline & 4 & $\begin{array}{l}\text { Saya mencoba untuk mengenal platform pembelajaran online yang ditawarkan sebelum } \\
\text { menggunakannya }\end{array}$ & $.471^{* *}$ \\
\hline & & Materi Pembelajaran & \\
\hline & 5 & $\begin{array}{l}\text { Sebelum belajar, saya biasanya memilih materi pembelajaran sesuai dengan tingkat } \\
\text { pengetahuan dan kemampuan teknologi saya. }\end{array}$ & $.377^{* *}$ \\
\hline & 6 & $\begin{array}{l}\text { Saya memilih metode belajar yang efektif berdasarkan inisiatif saya sendiri sesuai dengan } \\
\text { tujuan dan isi pembelajaran. }\end{array}$ & $.560^{* *}$ \\
\hline & 7 & $\begin{array}{l}\text { Saya selalu menetapkan tujuan pembelajaran berdasarkan latar belakang pengetahuan } \\
\text { yang saya miliki. }\end{array}$ & $.546^{* *}$ \\
\hline & & $\begin{array}{l}\text { Saya memilih materi pembelajaran secara fleksibel sesuai dengan tujuan pembelajaran } \\
\text { yang ditetapkan. }\end{array}$ & $.490^{* *}$ \\
\hline & & Hasil Belajar & \\
\hline & 9 & Saya memilih tempat belajar terlebih dahulu untuk mendapatkan efek belajar yang baik. & $.431^{* *}$ \\
\hline & 10 & $\begin{array}{l}\text { Saya memprediksi hasil belajar saya sesuai dengan kesulitan materi pembelajaran sejak } \\
\text { dimulainya pembelajaran jarak jauh }\end{array}$ & $.514^{* *}$ \\
\hline & 11 & Saya memperhitungkan cara menilai hasil belajar sejak pembelajaran jarak jauh & $.379^{* *}$ \\
\hline
\end{tabular}




\begin{tabular}{|c|c|c|c|}
\hline Dimensi SRL & $\begin{array}{c}\text { No } \\
\text { angket }\end{array}$ & Uraian & $\begin{array}{l}\text { Nilai } \\
\text { Korelasi } \\
\text { Pearson }\end{array}$ \\
\hline \multirow{16}{*}{$\begin{array}{l}\text { Kemampuan } \\
\text { Mengontrol }\end{array}$} & & Sumber Belajar & \\
\hline & & Saya selalu memikirkan keefektifan metode belajar saya selama pembelajaran jarak jauh & $.507^{* *}$ \\
\hline & & $\begin{array}{l}\text { Saya memastikan untuk mengikuti pengaturan jadwal dari waktu ke waktu selama } \\
\text { pembelajaran jarak jauh saya }\end{array}$ & $.538^{* *}$ \\
\hline & & $\begin{array}{l}\text { Saya merenungkan apakah ada masalah dengan cara saya mencari bantuan ketika saya } \\
\text { memiliki masalah yang belum terselesaikan }\end{array}$ & $.366^{* *}$ \\
\hline & & Saya sengaja memeriksa apakah materi pembelajaran yang digunakan bermanfaat. & $.355^{* *}$ \\
\hline & & $\begin{array}{l}\text { Saya berkomunikasi dengan guru dan teman untuk menilai apakah materi pembelajaran } \\
\text { efektif. }\end{array}$ & $.370^{* *}$ \\
\hline & & Materi Pembelajaran & \\
\hline & & $\begin{array}{l}\text { Saya mencoba mencari dan membaca kembali materi yang belum saya pahami } \\
\text { sepenuhnya. }\end{array}$ & $.558^{* *}$ \\
\hline & & $\begin{array}{l}\text { Jika ada acara favorit saya di TV saat saya melakukan pembelajaran jarak jauh, saya } \\
\text { memilih untuk tetap belajar daripada menonton TV. }\end{array}$ & $.386^{* *}$ \\
\hline & & $\begin{array}{l}\text { Dalam pembelajaran jarak jauh, saya selalu mencari tahu bagaimana meningkatkan prestasi } \\
\text { akademis saya. }\end{array}$ & $.599^{* *}$ \\
\hline & & Hasil Belajar & \\
\hline & & $\begin{array}{l}\text { Dalam proses pembelajaran jarak jauh, saya memeriksa sejauh mana penguasaan materi } \\
\text { pembelajaran saya secara berkala }\end{array}$ & $.590^{* *}$ \\
\hline & & Saya memeriksa kualitas pekerjaan rumah atau tugas belajar saya dengan mengkaji ulang. & $.526^{* *}$ \\
\hline & & Saya selalu memperhatikan apakah saya benar-benar memahami konten yang saya pelajari. & $.601^{* *}$ \\
\hline & & $\begin{array}{l}\text { Saya mengajak diri saya sendiri untuk menyelesaikan tugas belajar tepat waktu selama } \\
\text { pembelajaran jarak jauh saya }\end{array}$ & $.466^{* *}$ \\
\hline & & Saya jarang memperhatikan hasil belajar saya. & $-.297^{* *}$ \\
\hline \multirow{17}{*}{$\begin{array}{l}\text { Kemampuan } \\
\text { Pengaturan }\end{array}$} & & Sumber Belajar & \\
\hline & & $\begin{array}{l}\text { Saya mengorbankan sebagian waktu luang saya untuk menyelesaikan tugas-tugas } \\
\text { pembelajaran. }\end{array}$ & $.502^{* *}$ \\
\hline & & $\begin{array}{l}\text { Jika materi sulit dipahami secara umum, saya menggunakan berbagai cara untuk } \\
\text { mempelajari dan memahami kembali materi tersebut. }\end{array}$ & $.580^{* *}$ \\
\hline & & Saya biasanya akan terus belajar, bahkan jika sesuatu mengganggu lingkungan saya. & $.428^{* *}$ \\
\hline & & $\begin{array}{l}\text { Setelah periode pembelajaran jarak jauh, saya akan menyesuaikan ukuran reward dan } \\
\text { punishment, yang telah ditetapkan untuk diri saya sendiri sebelumnya, sesuai dengan situasi } \\
\text { pembelajaran yang sebenarnya. }\end{array}$ & $.597^{* *}$ \\
\hline & & $\begin{array}{l}\text { Setelah masa studi, saya melanjutkan untuk menambah materi pembelajaran baru sesuai } \\
\text { dengan studi saya dan saran dari orang lain }\end{array}$ & $.606^{* *}$ \\
\hline & & saya melakukan latihan / aktivitas yang diberikan di unit kursus. & $.441^{* *}$ \\
\hline & & Materi Pembelajaran & \\
\hline & & $\begin{array}{l}\text { Saya menyesuaikan urutan tugas pembelajaran sesuai dengan pembelajaran biasanya } \\
\text { selama pembelajaran jarak jauh }\end{array}$ & $.525^{*+}$ \\
\hline & & Saya menyesuaikan jadwal belajar sesuai dengan penguasaan materi yang dipelajari. & $.561^{* \star}$ \\
\hline & & Saya memilih beberapa materi yang lebih mudah dipelajari ketika saya merasa lelah. & $.426^{* *}$ \\
\hline & & $\begin{array}{l}\text { Saya mencoba menggunakan cara lain untuk mendapat bantuan saat menghadapi masalah } \\
\text { yang tidak terpecahkan. }\end{array}$ & $.435^{* *}$ \\
\hline & & Hasil Belajar & \\
\hline & & $\begin{array}{l}\text { Saya menyesuaikan metode belajar saya sesuai dengan kinerja saya selama pembelajaran } \\
\text { jarak jauh. }\end{array}$ & $.558^{* *}$ \\
\hline & & $\begin{array}{l}\text { Jika prestasi belajar saya tertinggal, saya berinisiatif untuk menurunkan pencapaian target } \\
\text { hasil belajar. (Begitu juga sebaliknya) }\end{array}$ & .065 \\
\hline & & $\begin{array}{l}\text { Setelah selasai belajar, saya menyesuaikan apa yang ingin saya capai sesuai saran guru } \\
\text { dan teman yang lain. atau selang periode belajar tertentu selesai, saya menyesuaikan apa } \\
\text { yang ingin saya capai sesuai saran guru dan teman yang lain. }\end{array}$ & $.456^{* *}$ \\
\hline & & $\begin{array}{l}\text { Dalam pembelajaran jarak jauh, saya menyesuaikan apa yang telah direncanakan dalam } \\
\text { menilai target belajar sesuai dengan pembelajaran yang dilakukan. }\end{array}$ & $.656^{* *}$ \\
\hline
\end{tabular}




\begin{tabular}{|c|c|c|c|}
\hline Dimensi SRL & $\begin{array}{c}\text { No } \\
\text { angket }\end{array}$ & Uraian & $\begin{array}{c}\text { Nilai } \\
\text { Korelasi } \\
\text { Pearson }\end{array}$ \\
\hline \multirow{19}{*}{$\begin{array}{l}\text { Kemampuan } \\
\text { Mengevaluasi }\end{array}$} & & Sumber Belajar & \\
\hline & & $\begin{array}{l}\text { Saya biasanya menilai kembali keputusan saya terhadap suatu materi, apakah efektif atau } \\
\text { tidaknya. }\end{array}$ & $.613^{* *}$ \\
\hline & & Selama PJJ, saya menilai kembali evaluasi yang cocok untuk dari target belajar saya & $.564^{* *}$ \\
\hline & & $\begin{array}{l}\text { Saya sering berpikir kembali sebelum benar-benar meminta bantuan untuk mendapatkan } \\
\text { cara memecahkan masalah akademik }\end{array}$ & $.382^{* *}$ \\
\hline & & Saya mengevaluasi waktu yang dibutuhkan setelah menyelesaikan setiap tugas. & $.647^{* *}$ \\
\hline & & Selama PJJ, saya mengevaluasi pengaruh faktor pengganggu di lingkungan belajar saya & $.440^{* *}$ \\
\hline & & $\begin{array}{l}\text { Pada akhir materi, saya mengevaluasi strategi untuk memerlukan bantuan tertentu untuk } \\
\text { melihat apakah saya telah membuat perbaikan. }\end{array}$ & $.605^{* *}$ \\
\hline & & Materi Pembelajaran & \\
\hline & & Pada setiap akhir materi, saya memiliki keyakinan akan penguasaan materi belajar & $.518^{* *}$ \\
\hline & & Saya selalu mengecek jadwal belajar dengan baik & $.552^{* *}$ \\
\hline & & $\begin{array}{l}\text { Saya selalu mengecek kesesuaian materi bacaan tambahan yang saya peroleh sendiri agar } \\
\text { sesuai dengan materi yang diberikan di sekolah }\end{array}$ & $.676^{* *}$ \\
\hline & & $\begin{array}{l}\text { Saya mengevaluasi kelayakan cara belajar yang saya gunakan untuk mencapai kompetensi } \\
\text { yang di harapkan. }\end{array}$ & $.605^{* *}$ \\
\hline & & $\begin{array}{l}\text { Saya selalu memeriksa urutan materi di sekolah dengan urutan materi dari bacaan } \\
\text { tambahan yang saya gunakan }\end{array}$ & $.574^{* *}$ \\
\hline & & $\begin{array}{l}\text { Saya mengevaluasi performa belajar saya pada pembelajaran jarak jauh di setiap akhir } \\
\text { pelajaran. }\end{array}$ & $.589^{* *}$ \\
\hline & & Hasil Belajar & \\
\hline & & $\begin{array}{l}\text { Saya sering berpikir kembali tentang rencana belajar harian atau mingguan yang saya } \\
\text { gunakan sudah sesuai. }\end{array}$ & $.570^{* *}$ \\
\hline & & $\begin{array}{l}\text { Di akhir studi, saya mengevaluasi pengaruh metode dan strategi pembelajaran yang saya } \\
\text { gunakan. }\end{array}$ & $.635^{* *}$ \\
\hline & & Saya mengevaluasi hasil belajar saya pada setiap akhir semester & $.646^{* *}$ \\
\hline & & $\begin{array}{l}\text { Setiap akhir semester, saya mengevaluasi harapan dari capaian yang telah ditetapkan di } \\
\text { awal semester. }\end{array}$ & $.648^{* *}$ \\
\hline
\end{tabular}

Skor angket SRL siswa pada dua kelompok perlakuan penerapan teori scaffolding dengan metode konvensional disajikan dalam tabel sebagai berikut:

Tabel 4. Kemandirian belajar siswa yang diberi perlakuan metode scaffolding dan konvensional

\begin{tabular}{lcc}
\hline \multirow{2}{*}{ Statistik } & \multicolumn{2}{c}{ grup } \\
\cline { 2 - 3 } & Scaffolding & Konvensional \\
\hline $\mathrm{n}$ & 27 & 27 \\
Means & 207.59 & 197.67 \\
Max & 242 & 222 \\
Min & 182 & 170 \\
Standar Deviasi & 17.524 & 16.342 \\
\hline
\end{tabular}

Hasil analisis deskriptif pada tabel 4 menunjukan bahwa siswa kelompok eksperimen dengan penerapan pendekatan scaffolding sudah tergolong cukup baik, sedangkan siswa kelompok kontrol dengan penerapan pembelajaran konvensional masih rendah.

Instrumen kemandirian belajar yang digunakan memiliki 4 dimensi yaitu; (1) Plan; (2) Control; (3) Regulation; dan (4) Evaluation. Berdasarkan 4 dimensi tersebut percentase SRL untuk kedua kelompok eksperimen dan kontrol diperoleh data sebagai berikut: 
Tabel 5. Persentase 4 Dimensi SRL untuk kedua kelompok eksperimen dan kontrol

\begin{tabular}{lccccc}
\hline \multirow{2}{*}{ Indikator } & Skor & \multicolumn{2}{c}{ Eksperimen } & \multicolumn{2}{c}{ Kontrol } \\
\cline { 3 - 6 } & Max & Means & $\%$ & Means & $\%$ \\
\hline Plan & 5 & 3.86 & $77.24 \%$ & 3.70 & $74.01 \%$ \\
Control & 5 & 3.83 & $76.70 \%$ & 3.77 & $75.45 \%$ \\
Regulation & 5 & 3.81 & $76.30 \%$ & 3.64 & $72.74 \%$ \\
Evaluation & 5 & 3.87 & $77.31 \%$ & 3.54 & $70.79 \%$ \\
\hline
\end{tabular}

Berdasarkan hasil analisis pada tabel 5 menunjukkan bahwa kelas dengan penerapan pendekatan scaffolding memiliki pensentase SRL lebih tinggi pada setiap dimensinya dibandingkan kelas kontrol dengan pembelajaran konvensional. Selanjutnya capaian persentase tiap dimensi SRL pada kelas eksperimen dengan penerapan pendekatan scaffolding lebih tinggi dibandingkan pada kelas kontrol dengan penerapan pembelajaran konvensional.

Selanjutnya hasil uji hipotesis dengan menggunakan program SPSS 21 uji-t untuk sampel bebas disajikan pada tabel 6.

Tabel 6. Hasil Uji Hipotesis dengan uji t data kemandirian belajar kedua kelompok eksperimen dan control

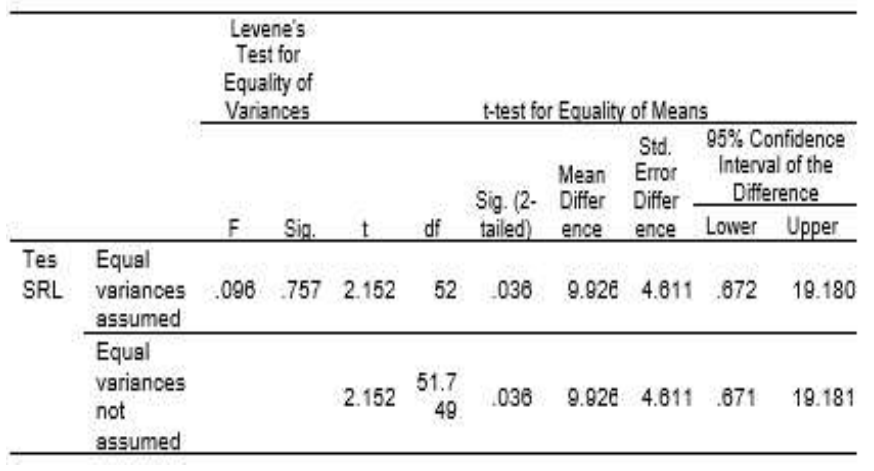

Hasil analisis tabel 6, menunjukkan bahwa harga statistik $\mathrm{F}=0,096$; $\mathrm{p}$-value $=0,757>0,05$ atau $\mathrm{H}_{\text {。 }}$ diterima. Dengan data SRL kelompok eksperimen dan kontrol memiliki varians sama atau homogen.

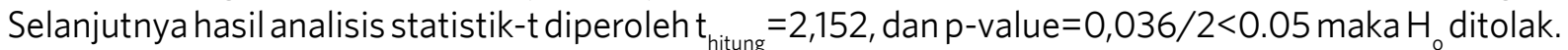
Sehingga dapat dinyatakan bahwa kemandirian belajar kelompok siswa yang diberikan pendekatan scaffolding lebih tinggi dibandingkan dengan kelompok siswa yang diberikan metode konvensional.

Temuan penelitian ini mengungkapkan bahwa secara umum siswa yang diajar menggunakan penerapan metode pembelajaran scaffolding lebih tinggi dibandingkan dengan kelompok siswa melalui penerapan pembelajaran konvensional. Temuan ini diperkuat dari temuan hasil persentase 4 dimensi SRL yaitu: Plan, Control, Regulation, dan Evaluation kelompok siswa yang diajar melalui penerapan pendekatan scaffolding memiliki persentase lebih tinggi dibandingkan kelompok siswa dengan penerapan pembelajaran konvensional.

Temuan penelitian ini serupa dengan temuan (Pramudyo Kusworo 2009) bahwa hasil penilaian ketiga aspek (afektif, psikomotorik, dan kognitif) dalam pembelajaran ekonomi di SMA Laboratorium Universitas Negeri Malang menunjukkan adanya peningkatan prestasi belajar siswa setelah penerapan scaffolding learning. Pembelajaran dengan scaffolding learning dapat meningkatan prestasi belajar siswa kelas X-3 SMA Laboratorium Universitas Negeri Malang. Peneitian serupa yang lain adalah penelitian (Nurhayati 2017) yang menyatakan bahwa kemandirian belajar siswa dengan pembelajaran yang menerapkan Scaffolding termasuk kriteria tinggi.

Temuan penelitian ini mengungkapkan bahwa capaian dimensi plan kelas ekperimen lebih tinggi dibandingkan kelompok kontrol. Pada dimensi Plan terlihat kemampuan siswa dalam mengenali kemampuan mereka sendiri, strategi yang diambil sebelum mereka mengambil keputusan dalam belajar. Berikutnya pada dimensi control capaian persentase kelompok siswa eksperimen juga lebih tinggi dibandingkan kelompok eksperimen, pada dimensi ini melihat kemampuan mengidentifikasi tugas, memantau, mengendalikan, dan memprediksi kemajuan tugas kognitif mereka. Pada dimensi 
Regulation yang mana merupakan kemampuan mengalokasikan sumber daya, membuat keputusan peraturan tentang langkah dan proses menyelesaikan tugas kognitif pada kelompok siswa eksperimen lebih tinggi dibandingkan kelompok kontrol. Begitu juga pada dimensi Evaluation yang merupakan kemampuan mengevaluasi hasil tugas kognitif, merenungkan merencanakan, mengendalikan, mengatur tugas, dan menginspirasi motivasi belajar masa depan pada siswa kelompok eksperimen lebih tinggi jika dibandingkan dengan kelompok kontrol.

Self Regulated learning didefinisikan sebagai kemampuan untuk berperilaku sesuai dengan niat seseorang dengan cara yang fleksibel menurut Kuhl (dalam Das, 2016). SRL menjembatani kesenjangan antara kinerja akademik dan dua penentunya yaitu: kemampuan kognitif dan motivasi berprestasi. Hal ini juga dipandang sebagai proses dimana siswa mengaktifkan dan mempertahankan kognisi, perilaku dan pengaruh yang secara sistematis berorientasi pada pencapaian tujuan mereka. Dalam hal perilaku, pembelajar mandiri memilih, menyusun dan bahkan menciptakan lingkungan sosial dan fisik yang mengoptimalkan proses akuisisi.

Dalam masa pembelajaran jarak jauh kemampuan SRL siswa perlu ditunjang dengan penerapan metode pembelajaran yang tepat. Dalam pembelajaran jarak jauh, karena pemisahan guru dan siswa dalam ruang dan/atau waktu, penting untuk menggunakan berbagai teknologi media untuk mencapai tujuan dalam pengajaran dan pembelajaran dan untuk membangun kembali interaksi. Dalam pembelajaran jarak jauh perlu diberdayakan menggunakan pembelajaran mandiri, guru menyediakan layanan pendukung pembelajaran yang diperlukan melalui berbagai cara, antara lain penerapan metode pembelajaran. Penerapan pembelajaran scaffolding sebagai metode yang memungkinkan seorang siswa untuk memecahkan masalah, melaksanakan tugas, atau mencapai tujuan yang akan berada di luar upaya tanpa bantuan guru sepenuhnya merupakan salah satu solusi. Guru hanya memberikan panduan dan penguatan. Sesuai dengan peranan guru yang diharapkan pada implementasi kurikulum 2013 yaitu student centered.

\section{SIMPULAN DAN SARAN}

Berdasarkan penelitian yang dilakukan diperoleh kesimpulan bahwa penerapan metode pembelajaran yang tepat dapat meningkatkan hasil belajar matematika pada pembelajaran jarak jauh saat ini. Penerapan pendekatan scaffolding sangat efektif dalam meningkatkan hasil belajar siswa pada pembelajaran jarak jauh karena siswa dituntun dalam memahami konsep matematika dengan terarah. Penerapan scaffolding membuat siswa belajar secara aktif dan ada interaksi dua arah antara siswa dan guru. Namun perlu terus ditingkatkan kemandirian belajar siswa dalam pembelajaran jarak jauh dengan bersinergi dengan orangtua dalam pembelajaran jarak jauh saat ini.

Saran untuk penelitian ini adalah perlu mengembangkan kemampuan IT untuk guru agar semakin bisa berinovasi dalam pembelajaran jarak jauh sehingga hambatan dalam BDR saat ini bisa teratasi. Siswa juga diharapkan dapat bekerjasama dalam penerapan metode pembelajaran yang dilakukan oleh guru saat pembelajaran jarak jauh ini.

\section{PUSTAKA ACUAN}

Cleary, Timothy J, and Barry J Zimmerman. 2004. "Self-Regulation Empowerment Program: A School-Based Program to Enhance SelfRegulated and Self-Motivated Cycles of Student Learning" 41, no. 5.

Das, Alaka. 2016. "Self Regulated Learning and Cognitive Styles of School Students - A Study" 5, no. 12: 1691-94.

Meyer, W R. 2010. "Independent Learning : A Literature Review and a New Project," no. September: 1-4.

Nurhayati, Elis. 2017. “Penerapan Scaffolding Untuk Pencapaian Kemandirian Belajar Siswa" 3, no. 1: 21-26.

Pramudyo Kusworo, Prih Hardianto. 2009. “Efektivitas Penerapan Pendekatan Pembelajaran Scaffolding Dalam Ketuntasan Belajar Ekonomi Siswa Kelas X SMA Laboratorium Universitas Negeri Malang." JPE 2.

Sumarni, Cicih, and Utari Sumarmo. 2016. "Penalaran Matematik Dan Kemandirian Belajar Siswa" 3, no. 3.

Zhao, Hong, and Santosh Panda. 2018. "Self-Regulated Learning Ability of Chinese Distance Learners," no. December. https://doi. org/10.1111/bjet.12118. 